\title{
Contact Mechanism of the Ag-doped Trimolyb- date Nanowire as An Antimicrobial Agent
}

\author{
Yujie Jiang ${ }^{1}$, Jian Gang ${ }^{1}$, Sheng-Yong $\mathrm{Xu}^{1, *}$
}

(Received 31 October 2012; accepted 15 November 2012; published online 30 November 2012)

\begin{abstract}
Antibacterial Ag-agents are intensively applied as broad spectrum, high-stability, high-efficiency and high-safety inorganic antibacterial agents. We have developed a new kind of antibacterial Ag-agent, namely $\mathrm{Ag}_{2-x}\left(\mathrm{NH}_{4}\right)_{x} \mathrm{Mo}_{3} \mathrm{O}_{10} \cdot 3 \mathrm{H}_{2} \mathrm{O}$ nanowires (NWs). Carrying $\mathrm{Ag}$ atoms in the lattice and $\mathrm{Ag}$-rich nanoparticles on the surface, the Ag-doped NWs show strong antibacterial effects for a variety of bacteria including $E$. coli, Staphylococcus aureus, Candida albicans and Aspergillus niger. By performing systematic comparison experiments, we have proven that the main antibacterial effects are neither resulted from the tiny amount of $\mathrm{Ag}^{+}$ions released from the Ag-doped NWs in aqueous solutions, nor resulted from Ag-rich nanoparticles of fragments of the NWs when they are slowly dissolved in the Martin broth. Instead, the effects are mainly resulted from a contact mechanism, under which, the Ag-doped NWs need to be physically in contact with the bacteria to be eliminated. This is a novel phenomenon observed in the interactions between nanomaterials and live cells, which is worthy of further investigation at the molecular scale. As the Ag-doped NWs are not dissolved in pure water or weak acids, one may find practical antibacterial applications in textile industry and food storage industry for these unique nanomaterials.
\end{abstract}

Keywords: Antibacterial agent; Antibacterial Ag-agent; Silver ions; Silver-rich nanoparticles; Silver-doped trimolybdate nanowire; Bio-safety of nanomaterials; Contact mechanism

Citation: Yujie Jiang, Jian Gang and Sheng-Yong Xu, "Contact Mechanism of the Ag-doped Trimolybdate Nanowire as An Antimicrobial Agent", Nano-Micro Lett. 4 (4), 228-234 (2012). http://dx.doi.org/10.3786/ nml.v4i4.p228-234

\section{Introduction}

Antibacterial agents are important materials that are intensively applied in hospitals, clinics, biological laboratories, medical and food industries, as well as in military practices and daily lives. There are natural antibacterial agents, organic antibacterial agents and inorganic antibacterial agents. Among inorganic antibacterial agents, the antibacterial Ag-agents that consist of element $\mathrm{Ag}$ have been widely investigated, and they are extensively applied in many cases as the first choice, because these Ag-agents usually inhibit low cost, broad spectrum, high stability, high efficiency, and above all, high safety [1-10].
To date two main effective parts have been recognized for the strong antibacterial properties of the Agagents: $\mathrm{Ag}^{+}$ions, and Ag-rich nanoparticles. For the antibacterial effects of $\mathrm{Ag}^{+}$ions, two kinds of mechanism have been reported. First, it is resulted from the toxic effects of the heavy element $\mathrm{Ag}^{+}$released from the agent. Second, it is attributed to the strong oxidization effects of reactive oxygen species (ROS) produced by $\mathrm{Ag}^{+}$, which consequently causes permanent damages on macromolecules or membrane of the bacterium [11-21]. On the other hand, the exact antibacterial mechanism of Ag-rich nanoparticles is not clear. However, at the molecular level one major difference has been reported: In the cells under test the Ag-rich

\footnotetext{
${ }^{1}$ Key Laboratory for the Physics and Chemistry of Nanodevices and Department of Electronics, Peking University, Beijing 100871, China

${ }^{1}$ These authors contributed equally to the paper.

*Corresponding author. E-mail: xusy@pku.edu.cn
} 
nanoparticles do not cause a dense DNA phenomenon, but it is always observed in $\mathrm{Ag}^{+}$treated cells [22-31].

We have reported that Ag-doped trimolybdate NWs, with a chemical formula of $\mathrm{Ag}_{2-\mathrm{x}}\left(\mathrm{NH}_{4}\right)_{\mathrm{x}} \mathrm{Mo}_{3} \mathrm{O}_{10} \cdot 3 \mathrm{H}_{2} \mathrm{O}$, have strong antibacterial effects. These NWs carry a certain amount of Ag atoms in the lattice and Ag-rich nanoparticles on the surface, and they can be synthesized at one-atmosphere from aqueous solutions. A 2-15 ppm concentration of the Ag-doped NWs in water could sufficiently eliminate the growth of E. coli and Staphylococcus aureus, while still being safe to certain kind of human cells [32]. The crystalline structure of the Ag-doped NWs is similar to the alkali family of trimolybdate NWs, namely $\Theta_{\mathrm{m}}\left(\mathrm{NH}_{4}\right)_{2-\mathrm{m}} \mathrm{Mo}_{3} \mathrm{O}_{10} \cdot \mathrm{nH}_{2} \mathrm{O}(\Theta=\mathrm{Li}, \mathrm{Na}, \mathrm{K}, \mathrm{Rb} ; \mathrm{m}=1$, $2)$. The Ag-doped NWs are hard to be dissolved in solutions with $\mathrm{pH}$ values of 2-9, but they can be dissolved in Martin broth [33].

However, it is not clear whether the antibacterial mechanism of the Ag-doped NWs is caused by the $\mathrm{Ag}^{+}$ ions, or by the Ag-rich particles released from the NWs, or it is due to other unknown mechanism. In this work, we have performed systematic experiments and revealed a contact mechanism for the antibacterial effects of the Ag-doped trimolybdate NWs.

\section{Experimental details}

We have followed the method reported previously to synthesize the Ag-doped trimolybdate NWs [32, 33]. Basically, the Ag-doped NWs were synthesized from a mixed aqueous solution of $\left(\mathrm{NH}_{4}\right)_{6} \mathrm{Mo}_{7} \mathrm{O}_{24} \cdot 4 \mathrm{H}_{2} \mathrm{O}(\mathrm{pu}-$ rity $99.999 \%$ ) and $\mathrm{AgNO}_{3}$ (purity 99.999\%) that were separately dissolved in de-ionized water. For each run, the masses of $\left(\mathrm{NH}_{4}\right)_{6} \mathrm{Mo}_{7} \mathrm{O}_{24} \cdot 4 \mathrm{H}_{2} \mathrm{O}$ and $\mathrm{AgNO}_{3}$ were typically $2 \mathrm{~g}$ and $0.25 \mathrm{~g}$, respectively, and the reaction temperature was set at $60 \pm 5^{\circ} \mathrm{C}$. After continuously stirring of the mixed solution for a few minutes, yellowish-white precipitates started to occur in the solution. The precipitates were collected, centrifuged and rinsed in de-ionized water for 6 cycles to get the pure NWs. The final solid samples were dried in air. The morphology and crystalline structures of the solid samples, recognized as Ag-doped trimolybdate NWs, were characterized by means of a field-emission scanning electron microscope (SEM, Tecnai XL30F) operated at $3-15 \mathrm{kV}$ and a transmission electron microscope (TEM, TecnaiG20) operated at $200 \mathrm{kV}$. The density of bacteria in the solution was determined with optical density measurement on a UV-2100 spectrophotometer (UNIC Optoelectronics Technology), operated at the wave length of $600 \mathrm{~nm}$. The measured data, referred as $\mathrm{OD}_{600}$ values, linearly indicated the colony density of bacteria about $1 \times 10^{9} \mathrm{cfu} / \mathrm{ml}$ at $\mathrm{OD}_{600}=1$. The inductive coupled plasma (ICP) spectrum was performed on a PROFILE SPEC (Leeman) atomic emission spectroscopy system. The culturing of various bacteria was performed following a standard biological procedure. A dozen groups of different experiments were done to figure out the antibacterial mechanism of the Ag-doped trimolybdate NWs.

In the first sets of experiments, we examined whether the antimicrobial effect of the Ag-doped NWs was resulted from the $\mathrm{Ag}^{+}$ions in the solution released from the NWs. To determine the concentration of $\mathrm{Ag}^{+}$ions in an aqueous solution of Ag-doped NWs, a suspension of $1 \mathrm{wt} \%$ Ag-doped NWs was prepared by adding $500 \mathrm{mg}$ NWs into $50 \mathrm{ml}$ de-ionized water, stirred thoroughly and kept for $24 \mathrm{hrs}$ at room temperature. After that, an acrodisc syringe filter with average pore diameter of $0.45 \mu \mathrm{m}$ (Article No. PN 4614, Pall Co.) was applied to filtrate the suspension. Then $10 \mathrm{ml}$ filtered solution was measured with an ICP atomic emission spectroscopy system. For comparison, we prepared 5 aqueous solutions of $\mathrm{AgNO}_{3}$ with $\mathrm{Ag}^{+}$ion concentrations of $44.7 \mathrm{ppm}, 18.6 \mathrm{ppm}, 7.76 \mathrm{ppm}, 3.66 \mathrm{ppm}$ and $0.7 \mathrm{ppm}$, respectively. Then $20 \mathrm{ml}$ of each of the six kinds of solutions were individually mixed with Martin medium powder, at a ratio of $1000 \mathrm{ml}$ to $28.5 \mathrm{~g}$. Each mixed solution was further mixed with $1 \mathrm{ml}$ of yeast suspension (namely Saccharomyces cerevisiae, showing an $\mathrm{OD}_{600}$ value of 0.4 ), and the final samples were cultured at $37^{\circ} \mathrm{C}$ for $24 \mathrm{hr}$.

Next, control experiments, namely Groups A, B and $\mathrm{C}$, were performed for culturing the same yeast sample. For Group A, we prepared mixture of Martin medium powders with $20 \mathrm{ml}$ de-ionized water. For Group B, a mixture of Martin medium powder was prepared with $20 \mathrm{ml}$ filtrate of the suspension of $1 \mathrm{wt} \% \mathrm{Ag}$-doped NWs in de-ionized water. For Group C, the Martin medium powder was mixed with a suspension of $100 \mathrm{ppm} \mathrm{Ag-}$ NWs in $20 \mathrm{ml}$ de-ionized water. The ratio of powder to solution for Groups A, B and C was all kept at $28.5 \mathrm{~g}$ to $1000 \mathrm{ml}$. Then $1 \mathrm{ml}$ yeast suspension (showing $\mathrm{OD}_{600}$ of 0.4) was added into each sample of Groups A, B and C. All these samples were cultured at $37^{\circ} \mathrm{C}$ for varied time up to $20 \mathrm{hrs}$, and their $\mathrm{OD}_{600}$ values were measured at different stages of the cultured samples. We have repeated this set of experiments for 3 times.

The $\mathrm{OD}_{600}$ method was applied to measure the dissolvability in time of the Ag-doped NWs in the Martin broth. Then 5 sets of samples were prepared to determine the solvent(s) for the Ag-doped NWs. In every $28.5 \mathrm{~g}$ of Martin powder, there were $5 \mathrm{~g}$ of tryptone, 2 $\mathrm{g}$ of yeast extract, $20 \mathrm{~g}$ of glucose, $1 \mathrm{~g}$ of $\mathrm{K}_{2} \mathrm{HPO}_{4}$ and $0.5 \mathrm{~g}$ of $\mathrm{MgSO}_{4}$. For each set of testing samples, $6 \mathrm{mg}$ Ag-doped NWs suspended in $20 \mathrm{ml}$ de-ionized water was mixed with one of the 5 ingredients of the Martin medium. Their $\mathrm{OD}_{600}$ values were measured at the time when the mixtures were just prepared, and at the time after they were treated in a shaker for $8 \mathrm{hrs}$. 
Finally, we examined whether the antimicrobial effect was resulted from Ag-rich nanoparticles released from the Ag-doped NWs, or the productions when the Agdoped NWs were dissolved in Martin broth. The Martin broth was prepared at a ratio of $1000 \mathrm{ml}$ de-ionized water to $28.5 \mathrm{~g}$ of Martin medium powder. First, the density change of the a $100 \mathrm{ppm}$ Ag-doped NWs suspension (i.e., $2 \mathrm{mg}$ Ag-doped NWs in $20 \mathrm{ml}$ Martin broth) was continuously measured over a period of 24 hrs by means of the $\mathrm{OD}_{600}$ method. Next, 4 groups of samples, namely Groups D, E, F and G, were prepared. The samples of Group D contained $20 \mathrm{ml}$ pure Martin broth. For Group E samples, the prepared suspension, where $2 \mathrm{mg} \mathrm{Ag}$-doped NWs were totally dissolved in 20 $\mathrm{ml}$ Martin broth, was filtered with the acrodisc syringe filter. Group F samples contained originally $100 \mathrm{ppm}$ solid Ag-doped NWs mixed with $20 \mathrm{ml}$ of Martin broth, and no filtering treatment was done. For samples in Group G, $20 \mathrm{ml}$ of pure Martin broth was filtered with the acrodisc syringe filter. Each sample was added $1 \mathrm{ml}$ of the same yeast (Saccharomyces cerevisiae, with original $\mathrm{OD}_{600}$ value of 0.4 ) suspension and was cultured at $37^{\circ} \mathrm{C}$. The samples were taken out at different culturing time from 0 to $10 \mathrm{hrs}$ for $\mathrm{OD}_{600}$ measurements. These sets of experiments were repeated for 3 times.
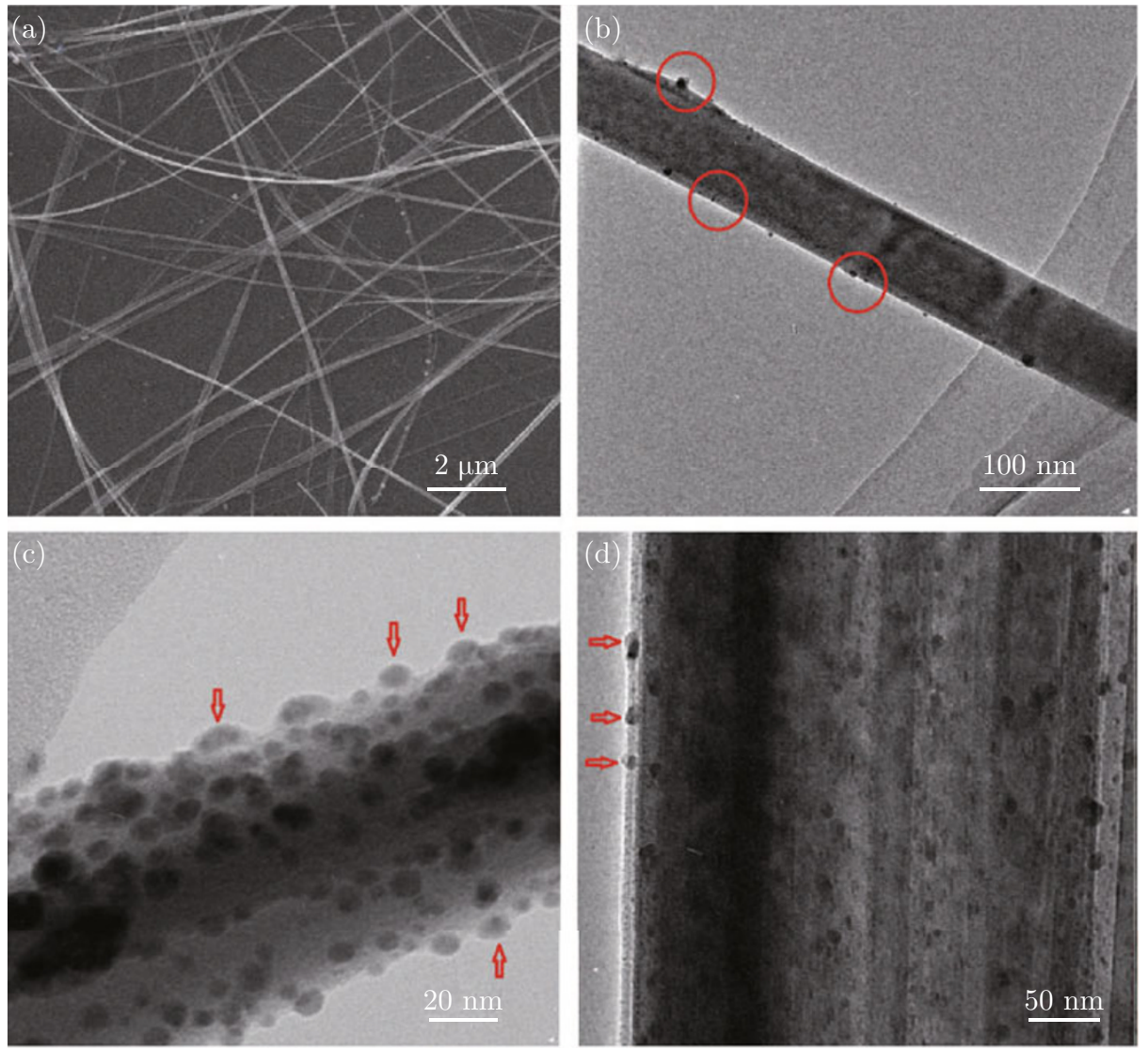

Fig. 1 (a) A SEM micrograph of the Ag-doped, $\mathrm{Ag}_{2-\mathrm{x}}\left(\mathrm{NH}_{4}\right)_{\mathrm{x}} \mathrm{Mo}_{3} \mathrm{O}_{10} \cdot 3 \mathrm{H}_{2} \mathrm{O}$ NWs. (b)-(d), TEM micrographs of individual Ag-doped NWs at different magnifications, where Ag-rich nanoparticles, appearing as dark dots in the images, are highlighted with red circles in (b) and with red arrows in (c) and (d). 
surface was not clean. As shown in Fig. 1(b) and 1(c), many dark nanoparticles were observed on the surface. These nanoparticles were characterized to be Ag-rich, probably being $\mathrm{Ag}_{2} \mathrm{O}$ nanoparticles [32]. As highlighted with red circles and arrows in Fig. 1(c) and 1(d), many Ag-rich nanoparticles were observed at the side of individual NWs, indicating these particles were located within the surface layer of the NS. We have confirmed this point by focusing a high-intensity electron beam of the TEM on individual Ag-doped NWs. After irradiation treatment of the high-intensity electron beam, the Ag-doped NW kept its shape, but many Ag-rich particles shifted away from their original positions.

As most Ag-doped NWs were much longer than 10 $\mu \mathrm{m}$, we expected that after filtrated with the acrodisc syringe filters, whose average pore diameter was 0.45 $\mu \mathrm{m}$, the Ag-doped NWs in the suspension were all removed from the remaining broth. That is, in the filtered solution, there were no Ag-doped NWs in their full lengths. If the NWs were partially of totally dissolved in the solvent, i.e., the Martin broth, however, besides molecules and molecule-clusters, there could be fragments of the dissolved NWs.

To examine whether the antimicrobial effect of the $\mathrm{Ag}$-doped NWs was resulted from the $\mathrm{Ag}^{+}$ions in the solution released from the NWs, we first measured the $\mathrm{Ag}^{+}$concentration in the suspension of $1 \mathrm{wt} \% \mathrm{Ag}-$ doped NWs in de-ionized water. The suspension was stirred thoroughly, kept for $24 \mathrm{hrs}$ and filtered with a $0.45 \mu \mathrm{m}$-pore filter. In the suspension the concentration of Ag-doped NWs (1 wt\%) was much higher than its minimum inhibitory concentration observed previously for antibacterial effect, which was 2-15 ppm [32, 33]. This setup ensured that, if $\mathrm{Ag}^{+}$ions could be released from the Ag-doped NWs, in the filtered solution one should found enough $\mathrm{Ag}^{+}$ions, and the solution should have obvious antibacterial effect. But the measured results were all negative. No antibacterial effects were observed by using the filtered solution. Indeed the concentration of $\mathrm{Ag}^{+}$ions in the filtered solution was only $1.7 \pm 0.3 \mathrm{ppm}$, as measured in ICP tests.

The low concentration of $\mathrm{Ag}^{+}$ions in the suspension of Ag-doped NW in water was confirmed by the control experiments, where antibacterial effects of aqueous $\mathrm{AgNO}_{3}$ solutions with $\mathrm{Ag}^{+}$ion concentrations from 0.7 ppm to $44.7 \mathrm{ppm}$ were systematically examined. The results showed that, $44.7 \mathrm{ppm}$ and $18.6 \mathrm{ppm}$ solutions of $\mathrm{Ag}^{+}$strongly eliminated the growth of yeasts, while in the rest 3 samples, with $\mathrm{Ag}^{+}$concentration of 7.76 ppm, $3.66 \mathrm{ppm}$ and $0.7 \mathrm{ppm}$, respectively, the antibacterial effects were weak. It showed that, under the conditions of our experiments, the minimum concentration of $\mathrm{Ag}^{+}$ion concentration for antibacterial application was somewhere between $18 \mathrm{ppm}$ and $7 \mathrm{ppm}$, a value much higher than the $1.7 \pm 0.3 \mathrm{ppm}$ measured from the suspensions of Ag-doped NWs.
Therefore, the results have shown that the tiny amount of $\mathrm{Ag}^{+}$ion released in aqueous solutions from the solid Ag-doped NWs is not the major antibacterial factor observed in our experiments [32, 33]. The aqueous solution of $\mathrm{Ag}^{+}$ions is known as a strong antibacterial agent. When the $\mathrm{Ag}^{+}$ions are in a Martin broth, the measured minimum concentration of $\mathrm{Ag}^{+}$for antibacterial effect in our experiments, around $10 \mathrm{ppm}$, was consistent with previous reports [36]. But under other conditions, the minimum concentration of $\mathrm{Ag}^{+}$ for showing moderate antimicrobial effects could be as low as $0.1 \mathrm{ppm}[34,35]$. The main reason could be the appearance of $\mathrm{K}_{2} \mathrm{HPO}_{4}$ in the Martin medium powder, which seems weakening the bactericidal effect of $\mathrm{Ag}^{+}$.

The experimental results samples of Group A, Group $\mathrm{B}$ and Group $\mathrm{C}$ are shown in Fig. 2, where roughly, the $\mathrm{OD}_{600}$ values of $0.4,1,3$ and 6 are calibrated as corresponding to the yeast densities of around $4 \times 10^{8}, 10^{9}$, $3 \times 10^{9}$ and $6 \times 10^{9} \mathrm{cfu} / \mathrm{ml}$, respectively. No difference is seen between the results of Group A and Group B. As the Group A samples are the standard, original materials for culturing bacteria, the results clearly indicate that the materials prepared for Group B do not have any antibacterial effect for yeast. In other words, the amount of $\mathrm{Ag}^{+}$ions in the sample, if there is any, is not enough to eliminate the growth of yeasts. In sharp contrast, in Group C samples the measured yeast density is obviously lower than those in Groups A and B. And, this low density looks not changing with the culturing time, indicating an excellent elimination of the growth of yeasts at the right beginning of the experiment. This confirmed the strong antibacterial effect of the Ag-doped NWs themselves. We repeated the

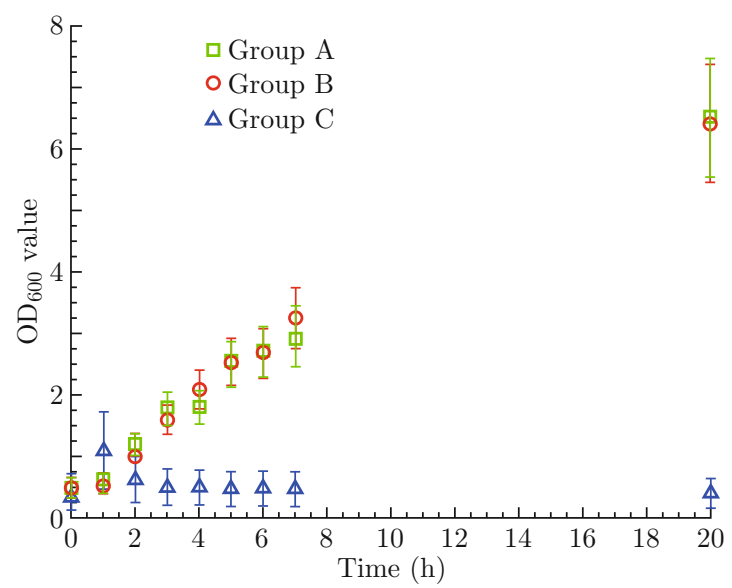

Fig. $2 \mathrm{OD}_{600}$ measurement results for density of bacterium samples of Groups A, B and C. For Group A, pure Martin broth is used. For Group B, the powder is mixed with 20 $\mathrm{ml}$ filtrate of the suspension of wt.1\% Ag-doped NWs in de-ionized water. For Group C, the powder is mixed with $100 \mathrm{ppm} \mathrm{Ag-NWs} \mathrm{in} 20 \mathrm{ml}$ de-ionized water. No evidence for antibacterial effect is observed in Groups A and B, but that for Group $\mathrm{C}$ shows a strong antibacterial effect. All experiments are repeated for 3 times. 
experiments three times, and obtained the consistent results.

A detail is noted in Fig. 2. In the first two hours, the yeast density in the Group $\mathrm{C}$ slightly increases and then it decreases to a value close to the original one. It may indicate that the NWs need some time to be effective for elimination of the growth of yeasts.

Figure 3 shows the solubility of the Ag-doped NWs in the aqueous solution of Martin broth powder. One sees that the $\mathrm{OD}_{600}$ value decreases rapidly with time. In 10-16 hrs the NWs are almost totally dissolved. Figure 4 shows the results that determine which of the five ingredients of the aqueous solution of Martin broth powder (tryptone, yeast extract, glucose, $\mathrm{K}_{2} \mathrm{HPO}_{4}$ and $\mathrm{MgSO}_{4}$ ) plays the key role for dissolving the Ag-doped NWs. The initial $\mathrm{OD}_{600}$ values of $6 \mathrm{mg}$ in the test solutions are all about 0.6. The $\mathrm{OD}_{600}$ values for $\mathrm{Ag}-\mathrm{NWs}$

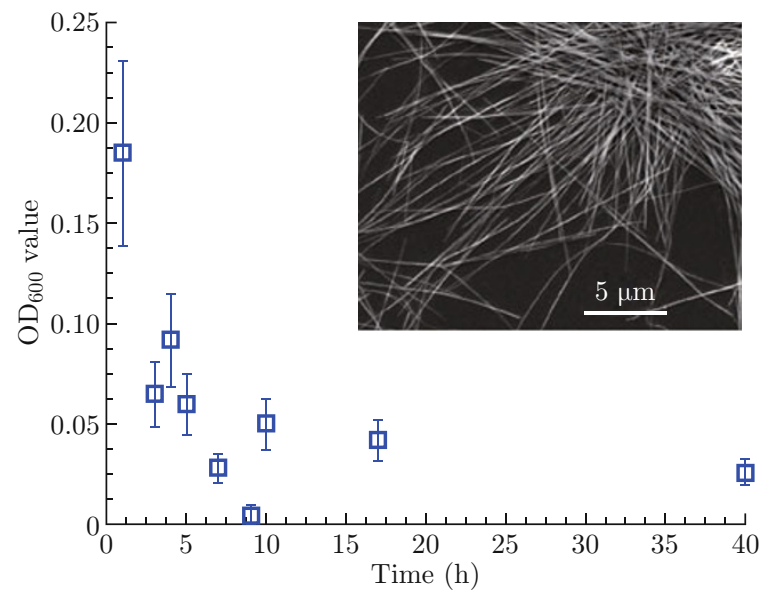

Fig. 3 The $\mathrm{OD}_{600}$ measurements results for $2 \mathrm{mg}$ Ag-doped NWs in $20 \mathrm{ml}$ Martin broth, showing the density of NWs remained in the solution decreases rapidly in time. After 10-16 hrs the NWs are almost totally dissolved. The inset shows a SEM micrograph of the Ag-doped NWs.

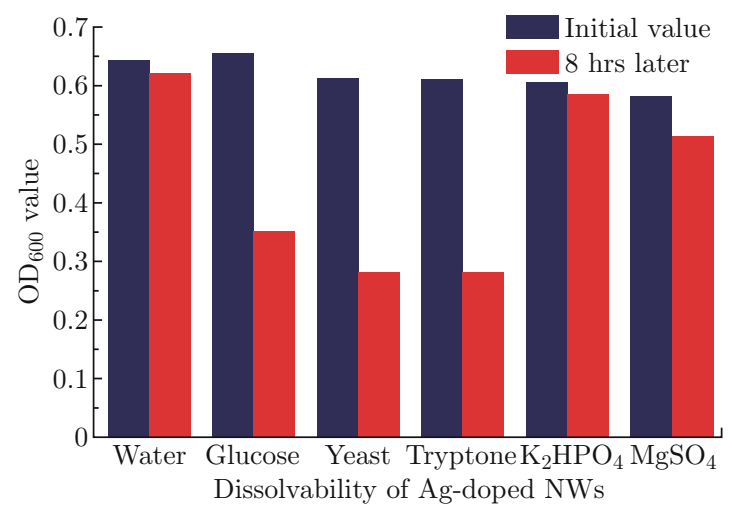

Fig. 4 A plot of the measurement results, showing which ingredient of a Martin broth being the solvent for dissolving Ag-doped NWs. Originally their $\mathrm{OD}_{600}$ values are the same. After $8 \mathrm{hrs}$, the $\mathrm{OD}_{600}$ values for $\mathrm{Ag}-\mathrm{NWs}$ mixed in tryptone, yeast extract and glucose decrease to around 0.3 , while the rest do not change much. mixed in tryptone, yeast extract and glucose decreased to around 0.3 after the samples had been shaken for 8 hrs in the solutions, indicating the NWs were partially dissolved in these three solvents. For samples mixed with $\mathrm{K}_{2} \mathrm{HPO}_{4}$ and $\mathrm{MgSO}_{4}$, the $\mathrm{OD}_{600}$ values did not change. So we conclude that the tryptone, yeast extract, glucose are the solvents for dissolving the Agdoped NWs. As there are nanoparticles on surface of the NWs and they may not be firmly attached to the NWs, there could be free Ag-rich nanoparticles in the solution after the NWs are dissolved. The following results reveal whether the possible free Ag-rich nanoparticles, fragments or any other productions in the solution, where the Ag-doped NWs have been dissolved in Martin broth, cause the antimicrobial effects.

Figure 5 plots the $\mathrm{OD}_{600}$ data showing yeast density in samples of Groups D, E, F and G. Group D samples are the blank control samples with the pure Martin broth, so the data indicate the normal growth trend of the yeasts over time. Within the measurement error, the samples of Groups D, E and G give the same yeast density at each time point, implying the materials prepared in Groups E and G have no antibacterial effects. But in Group F, where $2 \mathrm{mg}$ NWs were added for an original concentration of $100 \mathrm{ppm}$ Ag-NWs, strong antibacterial effect is seen. The main difference in these repeated experiments is that, in samples of Group F, there are solid Ag-doped NWs of original concentration of $100 \mathrm{ppm}$, while the samples of the rest groups originally contain no solid Ag-doped NWs.

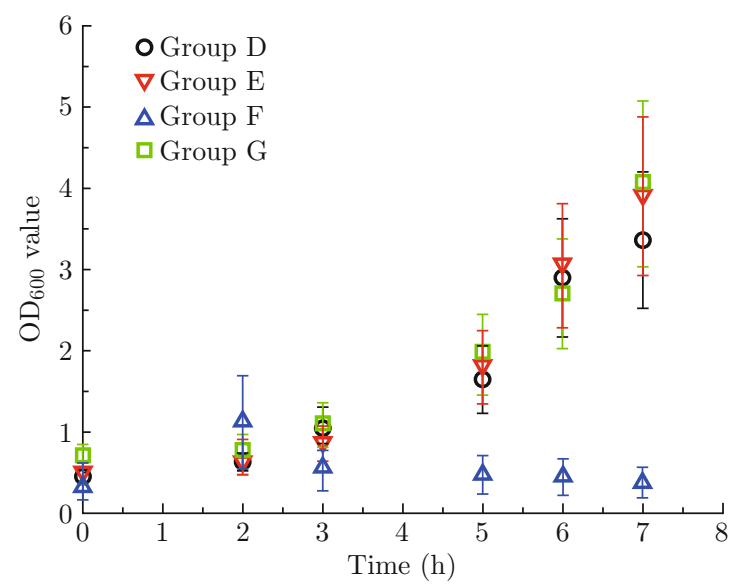

Fig. 5 The $\mathrm{OD}_{600}$ data measured from samples of Groups D, E, F and G. Clearly, yeasts grow well in samples of Groups D, E, and G, but not in samples of Group F. The main difference is, in samples of Group F, there are solid Ag-doped NWs of original concentration of 100 ppm, while the samples of the rest groups originally contain no solid Ag-doped NWs. All experiments are repeated for 3 times.

The data for Group F are quite similar to that for Group $\mathrm{C}$ shown in Fig. 2. Once again, the common point is that the materials prepared for Group C and Group F both contain a large amount of solid Ag-doped 
NWs. Also in a similar way, in the Group F the yeast density slightly increases in the first two hours then decreases to a value close to the original. These results have shown that the antimicrobial effect is neither caused by the nanoparticles, nor by the dissolving productions of the Ag-doped NWs in the Martin broth, but rather by the un-dissolved, solid Ag-doped NWs. It needs further investigation at the molecular level to understand how the solid Ag-doped NWs interplay with the bacteria under test.

Finally, the skin sensitivity tests showed that, after applying $0.5 \mathrm{ml}$ of $1000 \mathrm{ppm}$ Ag-doped NWs in deionized water on the rabbit skin for continuous 14 days, the skin stayed in good condition free of erythema or dropsy. This preliminary result implies a potential application for the solid, water-proof Ag-doped trimolybdate NWs as high-performance antibacterial agent in textile industry, e.g., as the surface agent of underwares and socks. They may also be used as the coating materials for the inner surface of food containers, e.g., a refrigerator.

\section{Conclusions}

In short, we have synthesized $\mathrm{Ag}_{2-\mathrm{x}}\left(\mathrm{NH}_{4}\right)_{\mathrm{x}} \mathrm{Mo}_{3} \mathrm{O}_{10}$. $3 \mathrm{H}_{2} \mathrm{O}$ NWs with the one-atmosphere, aqueous solution technique, and systematically studied the antimicrobial mechanism of these Ag-doped NWs for bacteria E. coli, Staphylococcus aureus, Candida albicans and Aspergillus niger. The Ag-doped NWs are not dissolvable in water, but can be slowly dissolved in the Martin broth, an agent for culture of bacteria. When wt.1\% of the Ag-doped NWs are mixed in de-ionized water and kept for $24 \mathrm{hrs}$, the $\mathrm{Ag}^{+}$ion concentration in the solution is around $1.7 \pm 0.3 \mathrm{ppm}$. We have confirmed that, this tiny amount of $\mathrm{Ag}^{+}$ions do not have obvious antibacterial effects under the setup of our experiments. We also confirmed that dissolved fragments of the Agdoped NWs in the Martin broth do not show obvious antibacterial effects. We show unambiguously that the antibacterial effects of the Ag-doped NWs are mainly resulted from a contact mechanism of the nanomaterials with the bacteria under test. This contact mechanism has been utilized to sense the occurrence of Ag-doped NWs in a diffusing process passing through porous ager medium [37]. In addition, this new phenomenon observed in the interactions between nanomaterials and live cells may have a potential for practical antibacterial applications in textile industry and food storage industry [38-40].

\section{Acknowledgement}

We are grateful to Prof. Jie Tang, Ms. Jiongwei Xue, Mo Chen, and Mr. Guolong Qu for valu- able discussions and Dr. Huayong Pan for assistant in TEM operation. SYX acknowledges the NSF of China (Grant No. 11074010) and the MOST of China (Grant No. 2011DFA51450) for financial support.

\section{References}

[1] H. Q. Tang, H. J. Feng, J. H. Zheng and J. Zhao, Sur. Coat. Technol. 201, 5633 (2007). http://dx.doi.org/ 10.1016/j.surf coat. 2006.07.171

[2] D. P. Dowling, A. J. Betts, C. Pope, M. L. McConnell, R. Eloy and M. N. Arnaud, Sur. Coat. Technol. 163, 637 (2003). http://dx.doi.org/10.1016/ S0257-8972 (02) 00689-8

[3] M. Kawashita, S. Tsuneyama, F. Miyaji, T. Kokubo, H. Kozuka and K. Yamamoto, Biomaterials 21, 393 (2000). http://dx.doi.org/10.1016/ S0142-9612(99)00201-X

[4] N. J. Coleman, J. Mater. Sci.: Mater. Med. 20, 1347 (2009). http://dx.doi.org/10.1007/ s10856-009-3698-0

[5] J. Zhao, H. J. Feng, H. Q. Tang and J. H. Zheng, Sur. Coat. Technol. 201, 5676 (2007). http://dx.doi.org/ 10.1016/j.surf coat. 2006.07.172

[6] B. L. Rivas, E. Pereira, C. Guzman and A. Maureira, Macromol. Symp. 46, 304 (2011).

[7] Y. Ilg and J. Kreyenschmidt, Int. J. Food Sci. Technol. 46, 1469 (2011). http://dx.doi.org/10.1111/j. 1365-2621.2011.02641. $\mathrm{x}$

[8] C. Y. Chen and C. L. Chiang, Mater. Lett. 62, 3607 (2008). http://dx.doi.org/10.1016/j.matlet. 2008.04 .008

[9] Y. Yi, Y. Wang and H. Liu, Carbohydr. Polym. 53, 425 (2003). http://dx.doi.org/10.1016/ S0144-8617 (03) 00104-8

[10] J. X. Li, J. Wang, L. R. Shen, Z. J. Xu, P. Li, G. J. Wan and N. Huang, Sur. Coat. Technol. 201, 8155 (2007). http://dx.doi.org/10.1016/ j.surfcoat. 2006.02.069

[11] C. P. Randall, L. B. Oyama, J. M. Bostock, I. Chopra and A. J. O'Neill, J. Antimicrob. Chemother. (2012).

[12] K. B. Holt and A. J. Bard, Biochemistry 44, 13214 (2005). http://dx.doi.org/10.1021/bi0508542

[13] Y. Zhang, Q. S. Yin, Y. Zhang, H. Xia, F. Z. Ai, Y. P. Jiao and X. Q. Chen, J. Mater. Sci.: Mater. Med. 21, 2453 (2010). http://dx.doi.org/10.1007/ s10856-010-4101-x

[14] P. Kaali, M. M. Pérez-Madrigal, E. Strömberg, R. E. Aune, Gy. Czél and S. Karlsson, Express Polymer Letters 5, 1028 (2011). http://dx.doi.org/10.3144/ expresspolymlett. 2011. 101

[15] J. P. Guggenbichler, M. BOswald, S. Lugauer and T. Krall, Infection 27, 16 (1999). http://dx.doi .org/10. 1007/BF02561612

[16] K. Yoshida, M. Tanagawa and M. Atsuta, Antibacterial Silver-supported Composite 47, 516 (1999).

[17] K. Kawahara, K. Tsuruda, M. Morishita and M. Uchida, Dental Materials 16, 452 (2000). http://dx. doi .org/10.1016/S0109-5641(00)00050-6 
[18] S. Y. Liau, D. C. Read, W. J. Pugh, J. R. Furr and A. D. Russell, Letters in Applied Microbiology 25, 279 (1997). http://dx.doi.org/10.1046/j. 1472-765X.1997.00219. $\mathrm{x}$

[19] W. J. Schreurs and H. Rosenberg, J. Bacteriol. 152, 7 (1982).

[20] P. Dibrov, J. Dzioba, K. K. Gosink and C. C. Hase, Antimicrobial Agents and Chemotherapy 46, 2668 (2002). http://dx.doi.org/10.1128/AAC.46.8. 2668-2670.2002

[21] W. Ghandour, J. A. Hubbard, J. Deistung, M. N. Hughes and R. K. Poole, Appl. Microbiol. Biotechnol. 28, 559 (1988). http://dx.doi.org/10.1007/ BF00250412

[22] J. R. Morones, J. L. Elechiguerra, A. Camacho, K. Holt, J. B. Kouri, J. T. Ramırez and M. J. Yacaman, Nanotechnology 16, 2346 (2005). http://dx.doi.org/ 10.1088/0957-4484/16/10/059

[23] H. J. Zhang and G. H. Chen, Environ. Sci. Technol. 34, 2905 (2009). http://dx.doi.org/10.1021/es803450f

[24] C. Aymonier, U. Schlotterbeck, L. Antonietti, P. Zacharias, R. Thomann, J. C. Tiller and S. Mecking, Chem. Commun. 3018 (2002). http://dx.doi. org/10.1039/b208575e

[25] P. K. Stoimenov, R. L. Klinger, G. L. Marchin and K. J. Klabunde, Langmuir 18, 6679 (2002). http://dx. doi.org/10.1021/la0202374

[26] C. N. Lok, C. M. Ho, R. Chen, Q. Y. He, W. Y. Yu, H. Sun, P. K. H. Tam, J. F. Chiu and C. M. Che, J. Proteome Res. 5, 916 (2006). http://dx.doi.org/10. 1021/pr0504079

[27] L. Balogh, D. R. Swanson, D. A. Tomalia, G. L. Hagnauer and A. T. McManus, Nano Lett. 1, 18 (2001). http://dx.doi.org/10.1021/n1005502p

[28] M. Rai, A. Yadav and A. Gade, Biotechnology Advances 27,76 (2009). http://dx.doi.org/10.1016/j. biotechadv. 2008.09.002

[29] I. Sondi and B. Salopek-Sondi, J. Colloid Interface Sci. 275, 177 (2004). http://dx.doi.org/10.1016/j. jcis. 2004.02 .012
[30] T. Klaus, R. Joerger, E. Olsson and C. G. Granqvist, PNAS. 96, 13611 (1999). http://dx.doi.org/10. 1073/pnas.96.24.13611

[31] J. P. Ruparelia, A. K. Chatterjee, S. P. Duttagupta and S. Mukherji, Acta Biomaterialia 4, 707 (2008). http://dx.doi.org/10.1016/j.actbio.2007.11.006

[32] J. W. Xue, J. W. Ye, Y. J. Jiang, M. Chen, H. Y. Pan, W. Wang, J. Tang and S. Y. Xu, International Scholarly Research Network Nanotechnology. V. 2012, Article ID 539601.

[33] J. W. Xue, Y. J. Jiang, J. Gang, M. Chen, J. W. Ye, H. Y. Pan and S. Y. Xu, J. Nanosci. Nanotechnol. 12, 7044 (2012). http://dx.doi.org/10.1166/jnn. 2012. 6498

[34] N. Silvestry-Rodriguez, E. E. Sicairos-Ruelas, C. P. Gerba and K. R. Bright, Rev. Environ. Contam. Toxicol. 191, 23 (2007). http://dx.doi.org/10.1007/ 978-0-387-69163-3_2

[35] H. S. Gao and Y. Z. Jin, Journal of Chemical Engineering of Chinese Universities 16, 80 (2002).

[36] Y. Matsumura, K. Yoshikata, S. Kunisaki and T. Tsuchido, Applied And Environmental Microbiology 69, 4278 (2003). http://dx.doi.org/10.1128/AEM. 69.7.4278-4281. 2003

[37] Y. J. Jiang, Jian Gang, J. W. Xue, S. Y. Xu, 2012 International Conference on Biomaterial and Bioengineering, Dec. 19-20, Hong Kong, China.

[38] C. C. Yang and C. T. Ko, Disinfectant adhesive tape, United States Patent Application Publication. 2008. Pub. No.: US 2008/0305136 A1.

[39] K. M. Paknikar, United States Patent Application Publication, Anti-microbial activity of biologically stabilized silver nano particles. 2007. Pub. No.: US 2007/0218555 A1.

[40] M. F. Rubner, S. Y. Yang, Y. Qiu, L. C. Winterton, J. M. Lally, Method for Making Medical Devices Having Antimicrobial Coatings Thereon, United States Patent Application Publication. 2005. Pub. No.: US 2005/0058844 A1. 